\title{
Resting heart rate as a marker for identifying the risk of undiagnosed type 2 diabetes mellitus: a cross-sectional survey
}

\author{
Yu-qian Li ${ }^{1}$, Chang-qing Sun ${ }^{2}$, Lin-lin Li ${ }^{2}$, Ling Wang ${ }^{2}$, Yi-rui Guo ${ }^{2}$, Ai-guo You ${ }^{3}$, Yuan-lin Xi ${ }^{2}$ and Chong-jian Wang ${ }^{2 *}$
}

\begin{abstract}
Background: Fast resting heart rate might increase the risk of developing type 2 diabetes mellitus (T2DM). However, it is unclear whether resting heart rate could be used to predict the risk of undiagnosed T2DM. Therefore, the purposes of this study were to examine the association between resting heart rate and undiagnosed T2DM, and evaluate the feasibility of using resting heart rate as a marker for identifying the risk of undiagnosed T2DM.
\end{abstract}

Methods: A cross-sectional survey was conducted. Resting heart rate and relevant covariates were collected and measured. Fasting blood samples were obtained to measure blood glucose using the modified hexokinase enzymatic method. Predictive performance was analyzed by Receiver Operating Characteristic (ROC) curve.

Results: This study included 16, 636 subjects from rural communities aged 35-78 years. Resting heart rate was significantly associated with undiagnosed T2DM in both genders. For resting heart rate categories of $<60,60-69$, $70-79$, and $\geq 80$ beats/min, adjusted odds ratios for undiagnosed T2DM were 1.04, 2.32, 3.66 and 1.05, 1.57, 2.98 in male and female subjects, respectively. For male subjects, resting heart rate $\geq 70$ beats/min could predict undiagnosed T2DM with $76.56 \%$ sensitivity and $48.64 \%$ specificity. For female subjects, the optimum cut-off point was $\geq 79$ beats/min with $49.72 \%$ sensitivity and $67.53 \%$ specificity. The area under the ROC curve for predicting undiagnosed T2DM was 0.65 (95\% Cl: 0.64-0.66) and 0.61(95\% Cl: 0.60-0.62) in male and female subjects, respectively.

Conclusions: Fast resting heart rate is associated with an increased risk of undiagnosed T2DM in male and female subjects. However, resting heart rate as a marker has limited potential for screening those at high risk of undiagnosed T2DM in adults living in rural areas.

Keywords: Marker, Resting heart rate, Type 2 diabetes mellitus

\section{Background}

Type 2 diabetes mellitus (T2DM) is a major public health problem causing significant morbidity and mortality in both developed and developing countries [1,2]. Previous research indicated that the aetiology of T2DM is complex and there are several risk factors associated with the disease occurrence [3,4]. In addition, T2DM has a latent nature in a large proportion of cases. Therefore, identifying factors that may predict risk of T2DM, especially undiagnosed T2DM is an important step toward improved understanding and prevention of this major disease in

\footnotetext{
*Correspondence: tjwcj2005@126.com

${ }^{2}$ Department of Epidemiology and Biostatistics, College of Public Health, Zhengzhou University, 100 Kexue Avenue, Zhengzhou 450001, Henan, PR China

Full list of author information is available at the end of the article
}

high-risk populations [5,6]. Blood glucose measurement with continuous monitoring is the standard method used to identify and diagnose T2DM [7], but it is not routinely used in resource limited settings, especially in rural areas of developing countries. Many individuals with T2DM remain undetected due to lack of affordability and availability of diagnostic equipment [8]. Therefore, a simple and inexpensive screening approach is necessary to identify those at high risk of undiagnosed T2DM in resource limited countries and areas.

Pulse rate is an easy measurement but important indicator of cardiovascular diseases. Many studies have shown that fast resting heart rate is an important marker of increased morbidity and mortality among people with cardiovascular diseases [9-12], which indicated that 
sympathetic over-activity may be a contributing factor to the development of cardiovascular diseases and diabetes [13]. Previous epidemiologic studies have shown that fast resting heart rate is an independent risk factor for the development of T2DM in Japanese individuals [14] and other populations [15-17]. These findings suggest that fast resting heart rate might have an increased risk for the development of T2DM. However, data from rural areas are limited and mainly from urban areas and developed countries. In addition, no study has been published exploring whether resting heart rate could be used as a marker to identify the risk of undiagnosed T2DM. Therefore, the purposes of the study were to examine and confirm the association between resting heart rate and undiagnosed T2DM, and evaluate the feasibility of using resting heart rate as a marker to screen those at high risk of undiagnosed T2DM in adults living in rural areas.

\section{Methods}

\section{Study population and samples}

The study was a population-based, cross-sectional survey, and subjects were selected cluster randomly from eligible candidates listed in the residential registration record from the rural district of Luoyang City in Henan Province of China, which has a population of 99.67 million by 2009, including rural population of 62.09 million, and urban population 37.58 million. The eligibility of the candidate was defined as those who were stable residents for at least 10 years in the areas aged $35-78$ years. Exclusion factors included participants with the following conditions within the past six months: 1 ) individuals with known diabetes, severe psychological disorders, physical disabilities, cancer, chronic kidney disease, Alzheimer's disease, or dementia; or 2) tuberculosis, acquired immune deficiency syndrome (AIDS), or other infectious diseases. The relevant information of the disease was obtained by the local rural healthcare practitioners. After known diabetes $(n=730)$, cancer $(n=48)$, chronic kidney disease $(\mathrm{n}=156)$, physical disabilities $(\mathrm{n}=9)$, Alzheimer's disease $(n=7)$, tuberculosis $(n=13)$, and other infectious diseases $(\mathrm{n}=11)$ were excluded, 16,754 subjects who met the criteria were enrolled in the study. Of the eligible participants, $118(0.70 \%)$ subjects were excluded because of missing information on resting heart rate $(n=71)$, blood glucose $(n=47)$. Ultimately, 16,636 subjects were selected for the present analysis. The procedure of the study was approved by the Zhengzhou University Medical Ethics Committee, and written informed consent was obtained from all participants.

\section{Data collection and laboratory measurement}

Data were collected by specially trained physicians and public health workers using standardized methods with stringent levels of quality control. A standardized questionnaire addressed information regarding demographics (age, sex, and residence), socioeconomic status (occupation, educational level, marital status, and individual annual income), family and individual disease history (hypertension, diabetes, heart disease, cancer, chronic kidney disease, stroke, tuberculosis, and AIDS), dietary and lifestyle (smoking, drinking, fat intake, vegetable and fruit intake, and physical activity). Details about the measurement methods and definitions of each variable have been published previously $[18,19]$. In brief, dietary intake data were collected from each subject using three-day diet records, and physical activity level was assessed by the International Physical Activity Questionnaire (IPAQ) [20]. Waist circumference (WC) was measured twice at the mid-point between the lowest rib and the iliac crest to the nearest $0.1 \mathrm{~cm}$, after inhalation and exhalation. In addition, the interview included questions related to the diagnosis and treatment of diabetes. Women were asked whether diabetes had been diagnosed during pregnancy and/or when they were not pregnant.

Blood pressure and pulse rates were measured using HEM-770A sphygmomanometer in the sitting position three times according to the American Heart Association's standardized protocol [21]. Participants were advised to avoid alcohol, cigarette smoking, coffee, tea, and excessive exercise for at least 30 minutes before their blood pressure measurement. Pulse pressure is the difference between systolic and diastolic blood pressure. The normal range of pulse pressure is from 20 to $60 \mathrm{mmHg}$, and the abnormal ranges is defined as a pulse pressure higher than $60 \mathrm{mmHg}$ or lower than $20 \mathrm{mmHg}$ according to the Chinese Hypertension Prevention Guide. Resting heart rate was classified into four categories: $<60,60-69,70-79$, and $\geq 80$ beats $/ \mathrm{min}$.

Blood specimens were collected with vacuum tubes containing sodium fluoride to determine plasma glucose after overnight fasting. Blood specimens were centrifuged at $4^{\circ} \mathrm{C}$ and $3000 \mathrm{rpm}$ for 10 minutes, and the plasma was transferred and stored at $-20^{\circ} \mathrm{C}$ for biochemical analyses. Plasma glucose was measured with a modified hexokinase enzymatic method (HTACHI automatic clinical analyzer, Model 7060, Tokyo, Japan).

\section{Definition of T2DM}

T2DM was defined as a self-reported history of diabetes or undiagnosed diabetes after excluding type 1 diabetes mellitus, gestational diabetes mellitus, and diabetes due to other causes. According to the American Diabetes Association (ADA) diagnostic criteria [22], previously undiagnosed T2DM was defined as having fasting plasma glucose $(\mathrm{FPG}) \geq 7.0 \mathrm{mmol} / \mathrm{L}$. All participants brought their prescribed medications during the clinic visit, and a self-reported history of diabetes was confirmed by the use of insulin or oral hypoglycemic agents. In 
addition, the hospitalized patients with diabetes had their charts reviewed.

\section{Statistical analysis}

Data are presented as mean \pm standard deviation (sd.). For continuous and categorical variables, differencebetween-group was determined by ANOVA test and chi-square $\left(X^{2}\right)$ test, respectively. Univariate and multivariate logistic regression models were built to quantify the risk of undiagnosed T2DM associated with resting heart rate adjusting for potential confounding and socioeconomic variables included age, education, occupation, marital status, individual income, smoking, drinking, fat intake, vegetable and fruit intake, family history of T2DM, waist circumference, physical activity, pulse pressure, and medication use. Receiver Operating Characteristic (ROC) was used to determine the best cut-off points for sensitivity and specificity. Area under the ROC curve (AUC) was also utilized to compare the combined sensitivity and specificity among different categories of subjects. All analyses were performed using SAS 9.1 (SAS Institute, USA). All reported $P$-values were two-sided, and $P$-values of less than 0.05 were considered to be statistically significant.

\section{Results}

Table 1 describes the general characteristics of the study sample stratified by gender. A total of 16, 636 subjects who met the criteria enrolled in the study. For male and female subjects, the mean ages (mean \pm sd.) were $54.51 \pm 11.06$ and $52.31 \pm 10.79$ years, respectively, and prevalence rates of undiagnosed T2DM were $4.33 \%$ and $5.26 \%$, respectively. The differences of the relevant parameters were compared, and the statistical significance were found about age, occupation, education level, physical activity, individual annual income, current smoking and drinking status, fat intake, vegetable and fruit intake, waist circumference, fasting glucose level, resting heart rate, and prevalence rate of undiagnosed T2DM between male and female $(P<0.01)$. However, marital status, pulse pressure, and family history of T2DM were similar between genders $(P>0.05)$.

Table 2 summarizes the unadjusted and adjusted odds ratios $(O R)$ and $95 \%$ Confidence Interval $(C I)$ of the risk of undiagnosed T2DM associated with resting pulse rate according to the four resting heart rate categories $(<60$, $60-69,70-79$, and $\geq 80$ beats $/ \mathrm{min}$ ). The results showed that resting heart rate and the risk of undiagnosed T2DM had a positively dose-response effect ( $P$ for trend $<0.01)$. After adjusting for age, education, occupation, marital status, individual income, smoking, drinking, fat intake, vegetable and fruit intake, family history of T2DM, waist circumference, physical activity, pulse pressure, and medication use, the $O R(95 \% C I)$ by providing the pulse rate categories staring from the reference category were 1.04 (0.57-1.87), 2.32 (1.33-4.03), and 3.66 (2.09-6.37) for male subjects, respectively. For female subjects, the $O R(95 \% C I)$ were 1.05 (0.56-1.97), 1.57 (0.86-2.86) and 2.98 (1.64-5.42), respectively.

Figure 1 presents the ROC curve of resting heart rate for identifying the risk of undiagnosed T2DM in male and female subjects. The AUC indicated that resting heart rate had a fairly poor separation for predicting those at high risk of undiagnosed T2DM in male (AUC $=0.65 \pm$ $0.02,95 \%$ CI: 0.64-0.66) and female (AUC $=0.61 \pm 0.01$, 95\% CI: 0.60-0.62) subjects.

Table 3 shows the sensitivity, specificity, positive likelihood ratio $(+\mathrm{LR})$, negative likelihood ratio $(-\mathrm{LR})$, positive predictive value (PPV), and negative predictive value (NPV) for different levels of resting heart rate cut-off in male and female subjects. Considering the best cut-off values of resting heart rate with the highest sensitivity and specificity combinations, a resting heart rate $\geq 70$ beats $/ \mathrm{min}$ was found to have maximal sensitivity (74.56\%) and specificity (48.64\%) for predicting those at high risk of undiagnosed T2DM in male subjects. For female subjects, the optimum cut-off point for predicting those at high risk of undiagnosed T2DM was a resting heart rate $\geq 79$ beats/min with $49.72 \%$ sensitivity and $67.53 \%$ specificity.

\section{Discussion}

In this large-scale, population-based cross-sectional survey, our findings showed that fast resting heart rate was associated with a moderate risk of undiagnosed T2DM for male and female subjects. However, resting heart rate as a marker had limited potential for screening those at high risk of undiagnosed T2DM in adults living in rural areas.

Fast heart rate or tachycardia is a signal from the sympathetic nervous system, a part of the autonomic nervous system, which is the body's fight or flight response that governs instinctive responses [23-25]. Increases in sympathetic activity elevate not only pulse rate but also blood glucose, and elevated blood glucose is a specific and pathologic feature of T2DM [14]. Therefore, chronic sympathetic over-activity might underlie the development of T2DM in subjects with tachycardia [26]. Moreover, autonomic dysfunction causing tachycardia and hypertension is an established and common complication of T2DM [26-28].

A recent research from the Australian Diabetes Obesity and Lifestyle (AusDiab) Study reported resting heart rate is associated with an increased risk of diabetes over a 5-year period, particularly among non-obese men [13]. An epidemiological study from the Chicago Heart Association Detection Project in Industry Study reported that resting heart rate in middle age was positively associated with diabetes diagnosis and diabetes mortality in older age [29]. Likewise, a positive association between 
Table 1 Baseline characteristics in male and female subjects $(n=16,636)$

\begin{tabular}{|c|c|c|c|}
\hline Variables & Male $(n=6,533)$ & Female $(n=10,103)$ & $P$ value \\
\hline Age (years), mean ( \pm sd) & $54.51(11.06)$ & $52.31(10.79)$ & 0.0001 \\
\hline Occupation, n (\%) & & & 0.0001 \\
\hline Farmers & $4613(70.61)$ & $9557(94.60)$ & \\
\hline Laborers & $1433(21.93)$ & $425(4.21)$ & \\
\hline Employers/managers & $487(7.45)$ & 121(1.20) & \\
\hline Education, n (\%) & & & 0.0001 \\
\hline No education & $420(6.43)$ & $2461(24.36)$ & \\
\hline Primary school & 2054(31.44) & $3666(36.29)$ & \\
\hline Middle school & $3101(47.47)$ & $3371(33.37)$ & \\
\hline High school & $855(13.09)$ & $568(5.62)$ & \\
\hline College and above & $103(1.58)$ & $37(0.37)$ & \\
\hline Marital status, n (\%) & & & 0.4178 \\
\hline Married/cohabitation & 5964(91.29) & $9186(90.92)$ & \\
\hline Divorced/widowed/unmarried & $569(8.71)$ & 917(9.08) & \\
\hline Physical activity, n (\%) & & & 0.0001 \\
\hline Low & 1665(25.49) & $3365(33.31)$ & \\
\hline Moderate & $1142(17.48)$ & $2432(24.07)$ & \\
\hline High & $3726(57.03)$ & $4306(42.62)$ & \\
\hline Mean individual income (annual), n (\%) & & & 0.0001 \\
\hline$<1000 \mathrm{CNY}$ & 2464(37.72) & $4050(40.09)$ & \\
\hline $1000-C N Y$ & 2033(31.12) & $3277(32.44)$ & \\
\hline$\geq 2000 \mathrm{CNY}$ & $2036(31.16)$ & $2776(27.48)$ & \\
\hline Current smoking, n (\%) & $3501(53.59)$ & $38(0.38)$ & 0.0001 \\
\hline Current drinking, n (\%) & $1721(26.34)$ & $63(0.62)$ & 0.0001 \\
\hline More high-fat diet, n (\%) & $627(9.60)$ & $285(2.82)$ & 0.0001 \\
\hline More vegetable and fruit intake, n (\%) & $3503(53.62)$ & $4756(47.08)$ & 0.0001 \\
\hline Family history of T2DM, n (\%) & $307(4.70)$ & $510(5.05)$ & 0.3093 \\
\hline Waist circumference $(\mathrm{cm})$, mean $( \pm \mathrm{sd})$ & $83.17(10.10)$ & $82.63(10.25)$ & 0.0006 \\
\hline Pulse pressure $(\mathrm{mmHg})$, mean $( \pm \mathrm{sd})$ & 47.89(11.62) & $48.02(14.11)$ & 0.5401 \\
\hline Fasting glucose (mmol/L), mean ( \pm sd) & $5.49(1.09)$ & $5.60(1.22)$ & 0.0001 \\
\hline Resting heart rate (beats/min), n (\%) & & & 0.0001 \\
\hline$<60$ & $706(10.81)$ & $361(3.57)$ & \\
\hline $60-$ & $2115(32.37)$ & $2344(23.20)$ & \\
\hline $70-$ & $2223(34.03)$ & $4026(39.85)$ & \\
\hline$\geq 80$ & 1489(22.79) & 3372(33.38) & \\
\hline Undiagnosed T2DM, n (\%) & $283(4.33)$ & $531(5.26)$ & 0.0070 \\
\hline
\end{tabular}

Abbreviations: sd standard deviation, CNY ChinaYuan, T2DM type 2 diabetes mellitus.

resting heart rate and incident T2DM was also observed in the Japanese population, and higher pulse rate might predispose to the development of obesity and T2DM [30]. However, the positive association between pulse rate and diabetes was not found in the Brazilian population [31], which could be explained by different ethical, racial, or geographic background, because resting heart rate and T2DM might be affected by their experiences of racism or concentration in particular geographical locations. In addition, a dose-response effect was also observed in the present study. Increasing resting heart rate categories were associated with a significantly increasing risk for undiagnosed T2DM (OR ranged from 1.05 to 3.66 in male and from 1.05 to 2.98 in female). This finding was similar to Zhang et al.'s study [16]. Overall, our findings were consistent with previous studies, and support the biological plausibility of a positive association between resting heart rate and the risk of undiagnosed T2DM.

Perhaps the most striking findings were the results of the sensitivity and specificity of resting heart rate as a 
Table 2 Univariate and multivariate analyses for the risk of undiagnosed T2DM associated with resting heart rate in male and female subjects $(n=16,636)$

\begin{tabular}{|c|c|c|c|c|}
\hline \multirow{2}{*}{ Variables } & \multicolumn{2}{|c|}{ Male $(n=6,533)$} & \multicolumn{2}{|c|}{ Female $(n=10,103)$} \\
\hline & Crude OR $(95 \% \mathrm{Cl})$ & Adjusted $O R(95 \% C l)^{\mathrm{a}}$ & Crude OR $(95 \% \mathrm{Cl})$ & Adjusted $O R(95 \% C l)^{\mathrm{a}}$ \\
\hline$<60$ & 1.00 & 1.00 & 1.00 & 1.00 \\
\hline $60-$ & $1.05(0.58-1.88)$ & $1.04(0.57-1.87)$ & $0.95(0.51-1.76)$ & $1.05(0.56-1.97)$ \\
\hline $70-$ & $2.35(1.36-4.06)$ & $2.32(1.33-4.03)$ & $1.37(0.76-2.48)$ & $1.57(0.86-2.86)$ \\
\hline$\geq 80$ & $3.78(2.19-6.53)$ & $3.66(2.09-6.37)$ & $2.47(1.37-4.45)$ & $2.98(1.64-5.42)$ \\
\hline$P$ for trend & $<0.001$ & $<0.001$ & $<0.001$ & $<0.001$ \\
\hline
\end{tabular}

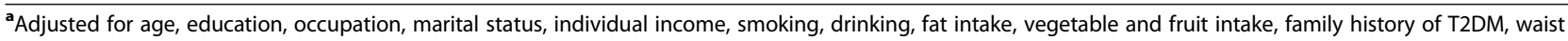
circumference, physical activity, pulse pressure, and medication use.

marker for identifying those at high risk of undiagnosed T2DM. Indeed, sensitivity and specificity are important when testing whether a marker can accurately discriminate positive and negative outcomes [32]. The ideal indicator should have both high sensitivity and high specificity [33]. However, in our study, resting heart rate as a marker demonstrated poor sensitivity (males with $74.56 \%$, and females with $49.72 \%$ ) and specificity (males with $48.64 \%$, and females with $67.53 \%$ ) for identifying true positive or negative patients in both genders of the adults living in rural areas. With these results, resting heart rate cannot be used to accurately screen undiagnosed T2DM patients.

Since AUC provides a superior performance index in addition to superior accuracy, it is often used to evaluate the predictive accuracy of classifiers [34]. The AUC of a classifier can be defined as the probability of the classifier to rank a randomly chosen positive example higher than a randomly chosen negative example, and the higher the AUC means higher accuracy $[34,35]$. This study also used AUC values for performance comparisons of different levels of resting heart rate. For male and female subjects, the AUC value indicated that resting heart rate had limited potential for screening elevated risk of undiagnosed
T2DM in terms of predictive accuracy, which suggested that resting heart rate as a marker for identifying undiagnosed T2DM had fairly poor accuracy and reliability in both genders of adults living in rural areas.

Although this is the first study to explore and evaluate the feasibility of using resting heart rate as a marker for identifying the risk of undiagnosed T2DM, some limitations should be mentioned. Firstly, the cross-sectional design does not offer support to causality statements, therefore, prospective studies for different populations are necessary to describe more accurately the longitudinal relationship between resting heart rate and undiagnosed T2DM. Secondly, the absence of oral glucose tolerance tests (OGTT) to identify and confirm T2DM patient, which should be considered in future research. Thirdly, the absence of thyroid function, left ventricular function or insulin measures to evaluate the relationship between resting pulse rate and glucose metabolism should be considered in future research. Fourth, only resting heart rate was used to identify those at high risk of undiagnosed T2DM in this study, and combination with other cardiovascular risk factor could screen more adequately subjects at increased risk to develop T2DM [14]. Another possible limitation is that resting heart
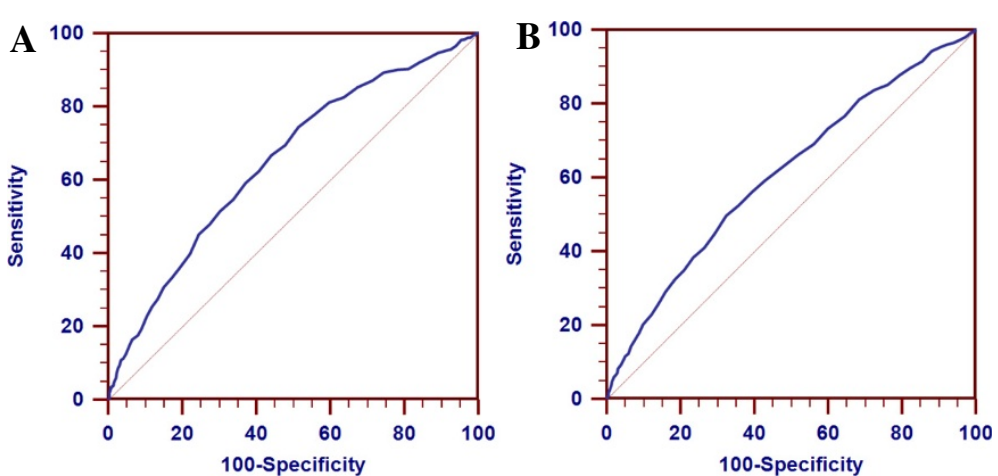

Figure 1 Receiver operating characteristic (ROC) curve of resting heart rate for identifying undiagnosed T2DM in male (A) and female (B) subjects. The areas under the ROC curves were $0.65 \pm 0.02$ and $0.61 \pm 0.01$ for male and female subjects, respectively, which suggested that resting heart rate had limited potential for screening undiagnosed T2DM. 
Table 3 Resting heart rate cut-off values for predicting undiagnosed T2DM in male and female subjects $(n=16,636)$

\begin{tabular}{|c|c|c|c|c|c|c|}
\hline Resting heart rate (beats/min) & Sensitivity & Specificity & +LR & $-\mathrm{LR}$ & PPV & NPV \\
\hline \multicolumn{7}{|l|}{ Male } \\
\hline 68 & 81.27 & 40.35 & 1.36 & 0.46 & 5.8 & 97.9 \\
\hline 69 & 78.09 & 44.14 & 1.40 & 0.50 & 6.0 & 97.8 \\
\hline 70 & 74.56 & 48.64 & 1.45 & 0.52 & 6.2 & 97.7 \\
\hline 71 & 69.61 & 52.14 & 1.45 & 0.58 & 6.2 & 97.4 \\
\hline 72 & 66.78 & 56.03 & 1.52 & 0.59 & 6.4 & 97.4 \\
\hline \multicolumn{7}{|l|}{ Female } \\
\hline 77 & 56.31 & 60.53 & 1.43 & 0.72 & 7.3 & 96.2 \\
\hline 78 & 52.24 & 64.22 & 1.47 & 0.74 & 7.5 & 96.1 \\
\hline 79 & 49.72 & 67.53 & 1.53 & 0.74 & 7.8 & 96.0 \\
\hline 80 & 44.82 & 70.82 & 1.54 & 0.78 & 7.9 & 95.9 \\
\hline 81 & 41.05 & 73.60 & 1.56 & 0.80 & 7.9 & 95.7 \\
\hline
\end{tabular}

rate was classified into four categories. This approach was chosen because it has been applied in previous epidemiological studies [30]. Despite these limitations, the results are based on a large population-based, epidemiological study after adjusting for potential confounders, and the exposure assessment of resting heart rate has been carried out systematically in this study, which precludes differential reporting in relation to the outcome.

\section{Conclusions}

Our findings demonstrated that fast resting heart rate was significantly associated with an increased risk of undiagnosed T2DM in both rural male and female adult population. More importantly, this data revealed that resting heart rate as a marker had limited potential for screening those at high risk of undiagnosed T2DM, which suggested that the resting heart rate might not be utilized as a perfect marker to identify the risk of undiagnosed T2DM in adults living in rural areas.

\section{Ethics approval}

Ethics approval was obtained from the Zhengzhou University Medical Ethics Committee, and written informed consent was obtained for all participants.

\section{What is already known on this topic?}

Fast pulse rate at rest might raise the risk for the development of type 2 diabetes mellitus (T2DM). However, data from rural areas are limited and mainly from urban areas and developed countries. In addition, no study has evaluated whether resting heart rate could be used as a marker for identifying the risk of undiagnosed T2DM.

\section{What does this study add?}

Our findings showed that fast resting heart rate was significantly associated with an increased risk of undiagnosed T2DM in both rural male and female adult population.
More importantly, these data revealed that resting heart rate as a marker had limited potential for screening those at high risk of undiagnosed T2DM, which suggested that it might not be served as a perfect marker to identify the risk of undiagnosed T2DM in adults living in rural areas.

\section{Abbreviations}

T2DM: Type 2 diabetes mellitus; WC: Waist circumference; ROC: Receiver operating characteristic; AUC: Area under the ROC curve; OR: odds ratios; Cl: Confidence interval.

\section{Competing interests}

The authors declare that they have no competing interests.

\section{Authors' contributions}

The following author contributions to the study are as follows. WCJ and LYQ conceived and designed the experiments. LYQ, SCQ, LLL, WL, GYR, YAG and $X Y L$ performed and conducted the experiments and reviewed/edited the manuscript. LYQ, LLL, GYR and YAG performed the statistical analysis of the data and reviewed/edited the manuscript. LYQ and WCJ wrote the manuscript. All authors read and approved the final version and its submission.

\section{Acknowledgements}

This research was supported by the National Natural Science Foundation of China (Grant NO: U1204823 \& U1304821), China Postdoctoral Science Foundation (Grant NO: 20100471003 \& 201104401), Medical Scientific Research Foundation of Health Department of Henan Province (Grant NO: 201204051 \& 201004042), and High-level Personnel Special Support Project of Zhengzhou University (NO: ZDGD13001). No competing financial interests exist. The authors thank all of the participants, coordinators, and administrators for their support and help during the research. In addition, the authors would like to thank Ms. Fatiha Karam (Doctoral Candidate) and Mr. Muanda FT (Doctoral Candidate) for their critical reading of the manuscript.

\section{Author details}

${ }^{1}$ Department of Clinical Pharmacology, School of Pharmaceutical Science, Zhengzhou University, Zhengzhou, Henan, PR China. 'Department of Epidemiology and Biostatistics, College of Public Health, Zhengzhou University, 100 Kexue Avenue, Zhengzhou 450001, Henan, PR China. ${ }^{3}$ Department of Disease Control and Prevention, Henan Provincial Center for Disease Control and Prevention, Zhengzhou, Henan, PR China. 


\section{References}

1. Nathan DM, Buse JB, Davidson MB, Ferrannini E, Holman RR, Sherwin R, Zinman B, American Diabetes Association, European Association for Study of Diabetes: Medical management of hyperglycemia in type 2 diabetes: a consensus algorithm for the initiation and adjustment of therapy: a consensus statement of the American Diabetes Association and the European Association for the Study of Diabetes. Diabetes Care 2009, 32:193-203.

2. Lin YP, LU TH: Trends in death rate from diabetes according to multiple-cause-of-death differed from that according to underlyingcause-of-death in Taiwan but not in the United States, 1987-2007. J Clin Epidemiol 2012, 65:572-576.

3. Walker M, Taylor R, Armstrong M, Turnbull DM: Complex aetiology of type 2 diabetes. Br J Hosp Med 1994, 52(4):179.

4. McCarthy Ml, Zeggini E: Genome-wide association scans for Type 2 diabetes: new insights into biology and therapy. Trends Pharmacol Sci 2007, 28(12):598-601.

5. World Health Organization: Screening for Type 2 Diabetes. Geneva: Report of a World Health Organization and International Diabetes Federation meeting; 2014. Available at: http://www.who.int/diabetes/publications/en/ screening_mnc03.pdf, Accessed October 10.

6. Norris SL, Kansagara D, Bougatsos C, Fu R, U.S. Preventive Services Task Force: Screening adults for type 2 diabetes: a review of the evidence for the U.S Preventive Services Task Force. Ann Intern Med 2008, 148:855-868.

7. Maran A, Pavan P, Bonsembiante B, Brugin E, Ermolao A, Avogaro A Zaccaria M: Continuous glucose monitoring reveals delayed nocturnal hypoglycemia after intermittent high-intensity exercise in nontrained patients with type 1 diabetes. Diabetes Technol Ther 2010, 12:763-768.

8. Colagiuri S, Hussain Z, Zimmet P, Cameron A, Shaw J, AusDiab: Screening for type 2 diabetes and impaired glucose metabolism: the Australian experience. Diabetes Care 2004, 27:367-371.

9. Hsia J, Larson JC, Ockene JK, Sarto GE, Allison MA, Hendrix SL, Robinson JG, LaCroix AZ, Manson JE, Women's Health Initiative Research Group: Resting heart rate as a low tech predictor of coronary events in women: prospective cohort study. BMJ 2009, 338:b219.

10. Rana JS, Hardison RM, Pop-Busui R, Brooks MM, Jones TL, Nesto RW, Bourassa MG, BARI 2D Investigators: Resting heart rate and metabolic syndrome in patients with diabetes and coronary artery disease in bypass angioplasty revascularization investigation 2 diabetes (BARI 2D) trial. Prev Cardiol 2010, 13:112-116.

11. Cheema BS, Marshall PW, Chang D, Colagiuri B, Machliss B: Effect of an office worksite-based yoga program on heart rate variability: a randomized controlled trial. BMC Public Health 2011, 11:578

12. Wang CJ, Li YQ, Li LL, Wang L, Zhao JZ, You AG, Guo YR, Li WJ: Relationship between resting pulse rate and lipid metabolic dysfunctions in Chinese adults living in rural areas [J]. PLOS One 2012, 7(11):e49347.

13. Grantham NM, Magliano DJ, Tanamas SK, Söderberg S, Schlaich MP, Shaw JE: Higher heart rate increases risk of diabetes among men: The Australian Diabetes Obesity and Lifestyle (AusDiab) Study. Diabet Med 2013, 30(4):421-427.

14. Nagaya $\mathrm{T}$, Yoshida $H$, Takahashi $H$, Kawai M: Resting heart rate and blood pressure, independent of each other, proportionally raise the risk for type 2 diabetes mellitus. Int J Epidemiol 2010, 39:215-222.

15. Linnemann B, Janka HU: Prolonged QTc interval and elevated heart rate identify the type 2 diabetic patient at high risk for cardiovascular death. The Bremen Diabetes Study. Exp Clin Endocrinol Diabetes 2003, 111:215-222.

16. Zhang X, Shu XO, Xiang YB, Yang G, Li H, Cai H, Gao YT, Zheng W: Resting heart rate and risk of type 2 diabetes in women. Int J Epidemiol 2010, 39:900-906

17. Bemelmans RH, Wassink AM, van der Graaf $Y$, Nathoe HM, Vernooij JW, Spiering W, Visseren FL, SMART Study Group: Risk of elevated resting heart rate on the development of type 2 diabetes in patients with clinically manifest vascular diseases. Eur J Endocrinol 2012, 166:717-725.

18. Wang CJ, Li YQ, Wang L, Li LL, Guo YR, Zhang LY, Zhang MX, Bie RH: Development and evaluation of a simple and effective prediction approach for identifying those at high risk of dyslipidemia in rural adult residents. PLOS One 2012, 7:e43834

19. Wang CJ, Li LL, Wang L, Ping ZG, Flory MT, Wang GS, Xi YL, Li WJ: Evaluating the risk of type 2 diabetes mellitus using artificial neural network: an effective classification approach [J]. Diabetes Res Clin Pract 2013, 100(1):111-118.
20. International Physical Activity Questionnaire: Short Last 7 Days Self-Administered Format 2005. 2014. Available at: http://www.ipaq.ki.se/downloads.htm, Accessed October 10.

21. Perloff D, Grim C, Flack J, Frohlich ED, Hill M, McDonald M, Morgenstern BZ: Human blood pressure determination by sphygmomanometry. Circulation 1993, 88:2460-2470.

22. American Diabetes Association: Diagnosis and classification of diabetes mellitus. Diabetes Care 2009, 32:S62-S67.

23. Cao WH, Morrison SF: Disinhibition of rostral raphe pallidus neurons increases cardiac sympathetic nerve activity and heart rate. Brain Res 2003, 980:1-10

24. Tentolouris N, Argyrakopoulou G, Katsilambros N: Perturbed autonomic nervous system function in metabolic syndrome. Neuromolecular Med 2008, 10:169-178.

25. Yar T: Resting heart rate and its relationship with general and abdominal obesity in young male Saudi University students. Pak J Physiol 2010, 6:6-13.

26. Landsberg L, Young JB: Insulin-mediated glucose metabolism in the relationship between dietary intake and sympathetic nervous system activity. Int J Obes 1985, 9:63-68.

27. Vinik Al, Ziegler D: Diabetic cardiovascular autonomic neuropathy. Circulation 2007, 115:387-397.

28. Vinik Al, Maser RE, Mitchell BD, Freeman R: Diabetic autonomic neuropathy. Diabetes Care 2003, 26:1553-1579.

29. Carnethon MR, Yan L, Greenland P, Garside DB, Dyer AR, Metzger B, Daviglus ML: Resting heart rate in middle age and diabetes development in older age. Diabetes Care 2008, 31:335-339.

30. Shigetoh $Y$, Adachi H, Yamagishi S, Enomoto M, Fukami A, Otsuka M, Kumagae S, Furuki K, Nanjo Y, Imaizumi T: Higher heart rate may predispose to obesity and diabetes mellitus: 20-year prospective study in a general population. Am J Hypertens 2009, 22:151-155.

31. Freitas Júnior IF, Monteiro PA, Silveira LS, Cayres SU, Antunes BM, Bastos KN, Codogno JS, Sabino JP, Fernandes RA: Resting heart rate as a predictor of metabolic dysfunctions in obese children and adolescents. BMC Pediatr 2012, 12:5

32. Ho WH, Lee KT, Chen HY, Ho TW, Chiu HC: Disease-free survival after hepatic resection in hepatocellular carcinoma patients: a prediction approach using artificial neural network. PLoS One 2012, 7:e29179.

33. Walker HK, Hal WD, Hurst JW: Clinical Methods: The History, Physical, and Laboratory Examinations (3rd edition). Boston, USA: Butterworth Publishers; 1990.

34. Fawcett T: An introduction to ROC analysis. Pattern Recogn Lett 2006, 27:861-874

35. Ke WS, Hwang Y, Lin E: Pharmacogenomics of drug efficacy in the interferon treatment of chronic hepatitis $C$ using classification algorithms. Adv Appl Bioinforma Chem 2010, 3:39-44.

doi:10.1186/1471-2458-14-1052

Cite this article as: Li et al:: Resting heart rate as a marker for identifying the risk of undiagnosed type 2 diabetes mellitus: a cross-sectional survey. BMC Public Health 2014 14:1052.

\section{Submit your next manuscript to BioMed Central and take full advantage of:}

- Convenient online submission

- Thorough peer review

- No space constraints or color figure charges

- Immediate publication on acceptance

- Inclusion in PubMed, CAS, Scopus and Google Scholar

- Research which is freely available for redistribution 